\title{
Epidemiological Features of Hospital Acquired Infection in a Tertiary Military Hospital
}

\author{
Muhammad Junayed Alam, ${ }^{1}$ A K M Mustafa Kamal Pasha ${ }^{2}$
}

\begin{abstract}
Background \& objective: Hospital Acquired Infections (HAIs) are the major concern in developing countries commonly affecting the ill patients in hospital settings. This study was conducted among the surgical patients admitted in the Combined Military Hospital (CMH), Dhaka to see the prevalence of HAI and factors influencing it.

Method: The present cross-sectional study was carried out on patients admitted in the Combined Military Hospital (CMH), Dhaka between 01 July to 31 December 2018 to find the epidemiological features of Hospital Acquired Infection (HAI). Patients who acquired infection while admitted in $\mathrm{CMH}$ in whom the infection was not present at admission or who were incubating pathogenic microorganisms at the time of admission and manifested signs and symptoms after discharge were the study population. However, psychologically abnormal patients were excluded. A total of 200 patients were selected consecutively. The variables included in the study were demographic characteristics, co-morbidity, immunosuppressive conditions, immunosuppressive therapy.
\end{abstract}

Result: Out 200 patients, 24(12\%) developed HAI. Analysis of demographic features revealed that age and sex of the patients did not act as determinants of HAI ( 0.378 and $p=0.635$ respectively). Patients dependent on others for most of their day-to-day activities tend to develop HAI more often than those who did not require assistance in their daily activities $(p=0.005)$. Patients inserted with an invasive device were more likely to develop HAI $(14.9 \%)$ than those who were not inserted with such devices $(7.6 \%)(p=0.121)$. The patients of chronic respiratory disease and diabetes mellitus frequently develop HAI than the patients with other illnesses $(p=0.040)$. Colostomy tube was the prime source of HAI $(50 \%)$ followed by gastrostomy tube $(33.3 \%)$, urinary catheter $(20.6 \%)$, orthopedic fixation device $(20 \%)$ and mechanical ventilation $(16.7 \%)(p<0.001)$ with longer the use of invasive devices the higher is the chance of HAI $(p=0.001)$. No association was observed between immunosuppressive condition of the patients and development of HAI $(p=0.558)$. Association between immunosuppressive therapy and HAI was not found to be significant $(p=0.495)$. HAI demonstrated their significant presence in patients with emergency operation compared to that in patients with routine operation $(p=0.047)$.

Conclusion: The study concluded that every one in eight patients admitted in CMH may develop HAI. Patients dependent on others for their daily activities and patients inserted with an invasive device more often develop HAI than those who are independent or without an invasive device. Patients of chronic respiratory disease and diabetes mellitus are more prone to develop HAI. Colostomy and gastrostomy tube also act as the main source of HAI. So does the urinary catheter, orthopedic fixation device and mechanical ventilation with longer the use of invasive devices the higher is the chance of HAI. Emergency operation also tends to be associated with HAI.

Key words: Hospital Acquired Infections (HAIs), epidemiological factors, Tertyiary Millitary Hospital etc

\section{INTRODUCTION:}

Hospital Acquired infection (HAI) can be defined as an infection occurring in a patient while admitted in a hospital or a health care facility in whom the infection was not present at the time of admission. This includes infections acquired in the hospital but appearing after discharge, and also occupational infections among staff of the facility. ${ }^{1}$ Despite immense progress in public health and hospital care, infections continue to develop in hospitalized patients without any concession. The effects of HAI are among the major causes of death and increased morbidity in both developed and developing countries resulting in significant burden both for patients \& hospital administration. The World Health Organization carried out a study in 2002 in 55 hospitals of the 14 countries and found an average of $8.7 \%$ of hospital patients with HAI. The situation is

\section{Authors' information:}

' Major (Dr.) Muhammad Junayed Alam, MPH (Hospital Management), DADMS, Head Quarter 10 Infantry Division, Ramu. ${ }^{2}$ Brigadier General (Dr.) A K M Mustafa Kamal Pasha, SPP, NDC (National Defence College), MPhil, MPH(Epidemiology), IG Prisons, Bangladesh. 
worst in Eastern Mediterranean and South East Asian region and accounted for figures of $11.8 \%$ and $10 \%$ respectively. ${ }^{2}$ As these infections occur during hospital stay, they cause prolonged stay, disability, and economic burden. ${ }^{1}$

Although modern medicine practiced in large urban hospitals in the $19^{\text {th }}$ century, opened up many avenues of hopes, overcrowding and ignorance added a significant risk of developing HAIs in patients undergoing multiple procedures ranging from child birth to amputation. ${ }^{3}$ However, in Bangladesh, a few studies have been conducted in this field. A study in 1990, found rate of HAI in Dhaka Medical College Hospital as 30\%. In 2003, the rate of infection in the same hospital was found to be $11.3 \%$. The studies revealed that $38.2 \%$ patients with HAI had to bear the burden of extra cost (1001-2000 Taka) because of longer hospital stay. ${ }^{4}$ In another study conducted to determine the microorganisms responsible for the HAI in different hospitals of Bangladesh found Staphylococcus aureus to be the most common pathogen with majority being resistant to multiple antibiotics. ${ }^{5} \mathrm{~A}$ study carried out in Combined Military Hospital (CMH), Dhaka in 2007 found HAI to be 8.3\%.6 The extent of problems and consequences of HAIs have been documented in several studies in USA where nearly two million patients are infected each year in the hospital. Of them 90 thousands die each year as a result of complications of HAI. Persons infected with drug-resistant organisms are more likely to have longer hospital stays and are treated with second or third line drugs that are less effective, more toxic and expensive. ${ }^{6}$

The patients with hospital-acquired infection suffer from functional disability and emotional stress leading to disabling conditions and reduced quality of life. The economic costs are also immense. Hospital-acquired infections add to the imbalance between resource allocation for primary and secondary health care by diverting scarce fund to the management of potentially preventable HAIs. Prolonged hospitalization of infected patients also results in decreased availability of hospital facilities for other patients with overall negative impact upon hospital practices. The costs of antibiotic increase due to management of HAIs, most of which is caused by drug-resistant bacterial strains. Increased mortality and length of hospital stay increases social and economic burden. ${ }^{2}$ The present study was, therefore intended to determine the epidemiological features of HAI in a Tertiary Care Military Hospital.

\section{METHODS:}

This cross-sectional analytical study was conducted on patients admitted in Surgical Units [General Surgery, Orthopedics, Urology, Neurosurgery, Obstetrics \& Gynaecology, Intensive Care Unit (ICU), High dependency unit (HDU), Cancer Center, Bone Marrow Transplantation Unit and Post-operative Wards] at Combined Military Hospital Dhaka over a period 6 months from July to December, 2018. The study population consisted mostly of military personnel (Army, Navy and Air Force) and a small number of civil employees paid from defense budget. The spouses and children of military personnel and civil employees as well as their parents were also included in the study. Patients who acquired infection while admitted in $\mathrm{CMH}$ in whom the infection was not present at admission or who were incubating pathogenic microorganisms at the time of admission and manifested signs and symptoms after discharge were the study population. However, psychologically abnormal patients and hospital staffs were excluded from the study. A total of 200 patients were selected consecutively. The variables included in the study were demographic characteristics, co-morbidity, immunosuppressive conditions \& immunosuppressive therapy.

A questionnaire and a checklist were prepared and were pre-tested among 10 admitted patients in the study hospital, for clarity, accuracy, unambiguity and to find out the face validity of the questions. Minor modifications of the questionnaire and the checklist were done following pretesting. After explaining the purpose of the study to the respondents, data were collected by the researcher himself through faceto-face interview. In addition, patient's medical records were reviewed and necessary information was recorded on the questionnaire and check-list. Data were analyzed using SPSS (statistical package for social sciences), version 20. The test statistics used to analyze the data were descriptive statistics 
like frequency with corresponding percentage, mean, median and standard deviation from the mean. Factors influencing HAI were analyzed using Chi-square $\left(\chi^{2}\right)$ or Fisher's Exact Test. The level of significance was et at $5 \%$ and $p$-value $<0.05$ was considered significant.

\section{RESULTS:}

Age distribution shows that the mean age of the respondents was $42.7 \pm 17.7$ years (range: $15-74$ years). Approximately $40 \%$ of the respondents were 50 or > 50 years old, $31 \% 15-29$ years, $29.5 \%$ 30-49 years. The respondents were predominantly male $(71 \%)$ with male to female ratio being roughly $7: 3$. Over half $(52.5 \%)$ of the respondents was secondary or equivalent level educated, $25 \%$ were higher secondary qualified, another $25 \%$ were class 6-10 qualified and $4 \%$ were illiterate. A total of $63(31.5 \%)$ respondents was military personnel, followed by $54(27 \%)$ retired army personnel, $36(18 \%)$ housewife, $19(9.5 \%)$ civil employee serving in Armed Forces. The mean monthly income of the respondents was taka $14287 \pm 10615$. Nearly three-quarters (74\%) of the respondents were married. Fifty five percent of the respondents had small family (2-4 members) and $34.5 \%$ had larger family comprising of $>4$ members (Table I).

The study subjects were mainly taken from the Departments of Orthopedics (26\%) and Gynae $(24.5 \%)$ followed by Surgery $(14.5 \%)$, Urology $(11 \%)$, Postoperative ward $(7.5 \%)$, Critical care unit (6\%) and less commonly from other wards, such as Neurosurgery, BMT, Cancer Center and HUD (Table II). Out of 200 respondents $121(60.5 \%)$ used invasive device. Of the invasive devices, intramuscular canula was most frequently used $(39.5 \%)$ followed by urinary catheter $(17 \%)$, orthopedic fixation device $(7.5 \%)$, nasogastric tube (4\%). Other less commonly used devices were mechanical ventilation, gastrostomy tube, colostomy tube and others (Table III).

Over $80 \%$ of the devices were used for $1-9$ days duration, $13.2 \%$ for $10-19$ days and $6.7 \%$ for 20 or $>20$ days duration (Table IV). Over one-third (34.5\%) had immunosuppressive conditions; $55(27.5 \%)$ were receiving immunosuppressive therapy. Nearly half (49\%) of the respondents have had surgery after admission; of them $80(81.6 \%)$ underwent routine surgery and the rest $18(18.4 \%)$ emergency surgery (Table V).

\begin{tabular}{|c|c|c|}
\hline $\begin{array}{l}\text { Socio-demographic } \\
\text { characteristic }\end{array}$ & Frequency & Percentage \\
\hline \multicolumn{3}{|l|}{ Age (years) } \\
\hline $15-30$ & 62 & 31.0 \\
\hline $30-50$ & 59 & 29.5 \\
\hline$\geq 50$ & 79 & 39.5 \\
\hline \multicolumn{3}{|l|}{ Sex } \\
\hline Male & 142 & 71.0 \\
\hline Female & 58 & 29.0 \\
\hline \multicolumn{3}{|l|}{ Education } \\
\hline Primary & 21 & 10.5 \\
\hline Secondary or equivalent & 105 & 52.5 \\
\hline Higher secondary or equivalent & 50 & 25.0 \\
\hline Graduation & 14 & 7.0 \\
\hline Post-graduation & 2 & 1.0 \\
\hline Illiterate & 8 & 4.0 \\
\hline \multicolumn{3}{|l|}{ Occupation } \\
\hline Military service & 63 & 31.5 \\
\hline Retired military service & 54 & 27.0 \\
\hline House wife & 36 & 18.0 \\
\hline Civil employee & 19 & 9.5 \\
\hline Students & 10 & 5.0 \\
\hline Others (Farmer, Electrician etc) & 18 & 9.0 \\
\hline \multicolumn{3}{|l|}{ Monthly income (taka) } \\
\hline$<10000$ & 50 & 25.0 \\
\hline 10000-19000 & 32 & 16.0 \\
\hline $20000-29000$ & 64 & 32.0 \\
\hline 30000 and above & 17 & 8.5 \\
\hline No income & 37 & 18.5 \\
\hline \multicolumn{3}{|l|}{ Marital status } \\
\hline Married & 148 & 74.0 \\
\hline Unmarried & 33 & 16.5 \\
\hline Others (Widower, Widow, Divorce) & 19 & 9.5 \\
\hline \multicolumn{3}{|l|}{ Family size } \\
\hline$<2$ & 21 & 10.5 \\
\hline $2-4$ & 110 & 55.0 \\
\hline$>4$ & 69 & 34.5 \\
\hline
\end{tabular}

Mean $=42.7 \pm 17.7$ years; range: $15-74$ years.

Eighteen (9\%) patients were admitted in ICU including Critical Care Center HDU. Table VI depicts the number of patients developed hospital acquired infection (HAI) and their type. Out of 200 respondents, 24(12\%) developed HAI; of them $6 \%$ 
had surgical site infection, $3 \%$ had urinary tract infection, $2 \%$ respiratory infection, $1 \%$ blood stream, skin and soft tissue infection). Aseptic measures taken by the hospital staff were evaluated using a check-list. Table VII depicts that $25 \%$ of the hospital staff washed their hand before touching a patient, 50\% washed their hands after touching a patient, $7.5 \%$ took hand washing after exposure to body-fluid of patients, and $25 \%$ took hand washing after touching the patients' surroundings and belongings. General cleanliness, cleanliness of the patients clothing and isolation of infectious patients were maintained $100 \%$ in the wards.

Table II. Distribution of respondents by admission in different wards

$\begin{array}{lcc}\text { Admission in different wards } & \text { Frequency } & \text { Percentage } \\ \text { Orthopedics } & 52 & 26.0 \\ \text { Gynae } & 49 & 24.5 \\ \text { Urology } & 29 & 14.5 \\ \text { Surgery } & 22 & 11.0 \\ \text { Post -operative } & 15 & 7.5 \\ \text { Critical care } & 12 & 6.0 \\ \text { Neurosurgery } & 7 & 3.5 \\ \text { BMT } & 5 & 2.5 \\ \text { Cancer center } & 5 & 2.5 \\ \text { HDU } & 4 & 2.0\end{array}$

Table III. Distribution of respondents by type of invasive devices used

\begin{tabular}{|lcc|}
\hline Invasive devices used & Frequency & Percentage \\
\hline Yes & 121 & 60.5 \\
Intravascular Cannula & 46 & 39.5 \\
Urinary Catheter & 34 & 17.0 \\
Orthopedic Fixation Device & 15 & 7.5 \\
Nasogastric Tube & 8 & 4.0 \\
Mechanical Ventilation & 6 & 3.0 \\
Gastrostomy Tube & 3 & 1.5 \\
Colostomy Tube & 2 & 1.0 \\
Others & 7 & 3.5 \\
No & 79 & 39.5
\end{tabular}

\begin{tabular}{|lcc|}
$\begin{array}{l}\text { Table IV. Distribution of respondents by duration of use of invasive } \\
\text { devices }(\mathbf{n}=\mathbf{1 2 1})\end{array}$ & Frequency & Percentage \\
\hline $\begin{array}{l}\text { Duration of invasive } \\
\text { devices used (in days) }\end{array}$ & 97 & 80.1 \\
$1-9$ & 16 & 13.2 \\
$10-19$ & 08 & 6.7 \\
$\geq 20$ &
\end{tabular}

Table V. Distribution of operated patients by type of operation $(n=98)$

$\begin{array}{lcc}\text { Type of operation } & \text { Frequency } & \text { Percentage } \\ \text { Routine } & 80 & 40.0 \\ \text { Emergency } & 18 & 9.0\end{array}$

\begin{tabular}{|lcc|}
\hline \multicolumn{3}{|c|}{ Table VI. Distribution of respondents by type of HAI ( $\mathbf{n = 2 0 0 )}$} \\
\hline HAl developed and its type & Frequency & Percentage \\
\hline Yes & 24 & 12.0 \\
Surgical site infection & 12 & 6.0 \\
Urinary Tract Infection & 6 & 3.0 \\
Respiratory Infection & 4 & 2.0 \\
Blood stream, skin and soft tissue infection & 2 & 1.0 \\
No & 176 & 88.0 \\
\hline
\end{tabular}

Table VII. Evaluation of aseptic measures adopted by the hospital staff

\begin{tabular}{|c|c|c|c|c|c|c|c|c|c|c|}
\hline Ward & 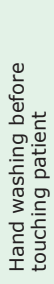 & 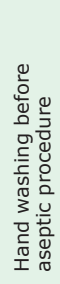 & 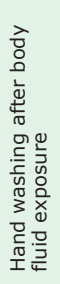 & 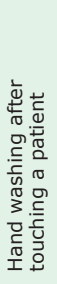 & 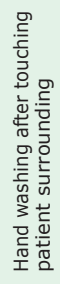 & 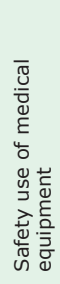 & 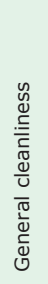 & 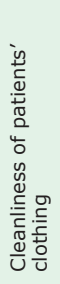 & 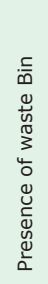 & 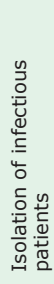 \\
\hline 1.Surgery & NO & YES & YES & No & NO & YES & YES & YES & YES & YES \\
\hline 2.BMT & YES & YES & YES & YES & YES & YES & YES & YES & YES & YES \\
\hline 3.Urology & No & YES & YES & YES & NO & YES & YES & YES & YES & YES \\
\hline 4.IIU & YES & YES & YES & YES & YES & YES & YES & YES & YES & YES \\
\hline 5.Gynae & NO & YES & YES & YES & NO & YES & YES & YES & YES & YES \\
\hline 6. Neuro surgery & No & YES & NO & NO & NO & YES & YES & YES & YES & YES \\
\hline 7.Cancer center & No & YES & YES & No & No & YES & YES & YES & YES & YES \\
\hline 8.0rthopedic & No & YES & YES & No & No & YES & YES & YES & YES & YES \\
\hline
\end{tabular}

Table VIII. Association between demographic features and HAI

\begin{tabular}{lccc} 
Demographic & \multicolumn{2}{c}{ HAI } & p-value \\
\cline { 2 - 3 } features & $\begin{array}{c}\text { Present } \\
(n=24)\end{array}$ & $\begin{array}{c}\text { Absent } \\
(n=176)\end{array}$ & \\
Age (years) & $6(9.7)$ & $56(90.3)$ & \\
$15-29$ & $10(16.9)$ & $49(83.1)$ & 0.378 \\
$30-49$ & $8(10.1)$ & $71(89.9)$ & \\
$>49$ & & & \\
Sex & $16(11.3)$ & $126(88.7)$ & 0.635 \\
Male & $8(13.8)$ & $50(86.2)$ & \\
Female & & &
\end{tabular}

Figures in the parentheses denote corresponding \%. Data were analyzed using Chi-square $\left(\chi^{2}\right)$. 


\begin{tabular}{|c|c|c|c|}
\hline \multirow{2}{*}{$\begin{array}{l}\text { Functional } \\
\text { status }\end{array}$} & \multicolumn{2}{|c|}{ HAI } & \multirow[b]{2}{*}{$\mathrm{p}$-value } \\
\hline & $\begin{array}{l}\text { Present } \\
(n=24)\end{array}$ & $\begin{array}{c}\text { Absent } \\
(n=176)\end{array}$ & \\
\hline Self help & $5(5.2)$ & 91(94.8) & \multirow{2}{*}{0.005} \\
\hline Require Assistance & 19(18.1) & 85(81.9) & \\
\hline
\end{tabular}

Figures in the parentheses denote corresponding percentage. Data were analyzed using Chi-square $\left(\chi^{2}\right)$.

\begin{tabular}{lccc} 
Table X. Association between $\mathrm{HAI}$ and invasive device application \\
\cline { 2 - 3 } $\begin{array}{l}\text { Invasive device } \\
\text { application }\end{array}$ & $\begin{array}{c}c \\
\text { Present } \\
(\mathrm{n}=24)\end{array}$ & $\begin{array}{c}\text { Absent } \\
(n=176)\end{array}$ & p-value \\
Yes & $18(14.9)$ & $103(85.1)$ & 0.121 \\
No & $6(7.6)$ & $73(92.4)$ &
\end{tabular}

Figures in the parentheses denote corresponding percentage. Data were analyzed using Chi-square $\left(\chi^{2}\right)$.

\begin{tabular}{llll} 
Table XI. Association between type of underlying illnesses and HAI \\
\cline { 2 - 3 } $\begin{array}{l}\text { Type of } \\
\text { underlying illness }\end{array}$ & $\begin{array}{c}c \\
\text { PAI } \\
(n=24)\end{array}$ & $\begin{array}{c}\text { Absent } \\
(n=176)\end{array}$ & p-value \\
Cerebrovascular Disease & $0(0.0)$ & $6(100.0)$ & \\
Coronary Heart Disease & $3(25.0)$ & $9(75.0)$ & \\
Chronic Genitourinary disease & $2(7.1)$ & $26(92.9)$ & \\
Endocrine Disease & $3(50.0)$ & $3(50.0)$ & \\
Malignancy & $1(7.7)$ & $12(92.3)$ & 0.040 \\
Chronic Respiratory Disease & $2(66.7)$ & $1(33.3)$ & \\
Gastrointestinal Disease & $3(13.0)$ & $20(87.0)$ & \\
Musculoskeletal Disease & $6(10.7)$ & $50(89.3)$ & \\
Gynaecological Disease & $4(8.3)$ & $44(91.7)$ & \\
ENT Disease & $0(0.0)$ & $5(100.0)$ &
\end{tabular}

Figures in the parentheses denote corresponding percentage. Data were analyzed using Chi-square $\left(\chi^{2}\right)$.

\begin{tabular}{|c|c|c|c|}
\hline \multirow[b]{2}{*}{ Name of device } & \multicolumn{2}{|c|}{ HAI } & \multirow[b]{2}{*}{$\mathrm{p}$-value } \\
\hline & $\begin{array}{l}\text { Present } \\
(n=24)\end{array}$ & $\begin{array}{c}\text { Absent } \\
(n=176)\end{array}$ & \\
\hline Gastrostomy Tube & $1(33.3)$ & $2(66.7)$ & \\
\hline Nasogastric Tube & $0(0.0)$ & $8(100.0)$ & \\
\hline Intravascular Cannula & $3(6.5)$ & $43(93.5)$ & \\
\hline Urinary Catheter & $7(20.6)$ & $27(79.4)$ & $<0.001$ \\
\hline Orthopedic Fixation Device & $3(20.0)$ & $12(80.0)$ & \\
\hline Mechanical Ventilation & $1(16.7)$ & $5(83.3)$ & \\
\hline Colostomy Tube & $1(50.0)$ & $1(50.0)$ & \\
\hline Others & $2(28.6)$ & $5(71.4)$ & \\
\hline
\end{tabular}

Figures in the parentheses denote corresponding percentage. Data were analyzed using Chi-square $\left(\chi^{2}\right)$.

\begin{tabular}{|c|c|c|c|}
\hline \multirow{2}{*}{$\begin{array}{l}\text { Immunosuppressive } \\
\text { condition }\end{array}$} & \multicolumn{2}{|c|}{ Hospital Acquired Infection } & \multirow[b]{2}{*}{$\mathrm{p}$-value } \\
\hline & $\begin{array}{l}\text { Present } \\
(n=24)\end{array}$ & $\begin{array}{c}\text { Absent } \\
(n=176)\end{array}$ & \\
\hline Yes & $7(10.1)$ & $62(89.9)$ & \multirow{2}{*}{0.558} \\
\hline No & $17(13.0)$ & $114(87.0)$ & \\
\hline
\end{tabular}

Figures in the parentheses denote corresponding percentage. Data were analyzed using Chi-square $\left(\chi^{2}\right)$.

\begin{tabular}{|c|c|c|c|}
\hline \multirow{2}{*}{$\begin{array}{l}\text { Immunosuppressive } \\
\text { Therapy }\end{array}$} & \multicolumn{2}{|c|}{ Hospital Acquired Infection } & \multirow[b]{2}{*}{ p-value } \\
\hline & $\begin{array}{l}\text { Present } \\
(n=24)\end{array}$ & $\begin{array}{c}\text { Absent } \\
(n=176)\end{array}$ & \\
\hline Yes & $8(14.5)$ & $47(85.5)$ & \multirow{2}{*}{0.495} \\
\hline No & $16(11.0)$ & $129(89.0)$ & \\
\hline
\end{tabular}

Figures in the parentheses denote corresponding percentage. Data were analyzed using Chi-square $\left(\chi^{2}\right)$.

\begin{tabular}{|c|c|c|c|}
\hline \multirow{2}{*}{$\begin{array}{l}\text { Type of } \\
\text { operation }\end{array}$} & \multicolumn{2}{|c|}{ Hospital Acquired Infection } & \multirow[b]{2}{*}{$p$-value } \\
\hline & $\begin{array}{l}\text { Present } \\
(n=24)\end{array}$ & $\begin{array}{c}\text { Absent } \\
(n=176)\end{array}$ & \\
\hline Routine & $11(13.8)$ & $69(86.2)$ & \multirow{2}{*}{0.047} \\
\hline Emergency & 6(33.3) & $12(66.7)$ & \\
\hline
\end{tabular}

Figures in the parentheses denote corresponding percentage. Data were analyzed using Chi-square $\left(\chi^{2}\right)$.

Analysis of demographic features revealed that age of the patients did not act as a determinant of HAI (0.378). Also, there was no significant association between gender and hospital acquired infection ( $p=0.635$ )(Table VIII). Respondents who required assistance for most of their daily activities tend to develop HAI more often than those who did not take assistance in their daily activities ( $p=0.005$ ) (Table IX). The patients inserted with an invasive device were more prone to develop HAI $(14.9 \%)$ than those who were not inserted with such devices (7.6\%) $(p=0.121)$ (Table $X)$. The patients of chronic respiratory disease and diabetes mellitus were more likely to develop HAI than the patients with other illnesses ( $p=0.040$ ) (Table XI). Colostomy tube was the main source of HAI (50\%) followed by gastrostomy tube $(33.3 \%)$, urinary catheter $(20.6 \%)$, orthopedic fixation device (20\%) and mechanical ventilation (16.7\%). Association between duration of use of invasive device and HAI 
was statistically significant ( $p=0.001$ ) (Table XII). No association was observed between immunosuppressive condition of the patients and development of HAI $(p=0.558)$ (Table XIII). Association between immunosuppressive therapy and HAI was not found to be significant ( $p=0.495$ ) (Table XIV). HAI demonstrated their significant presence in patients with emergency operation compared to that in patients with routine operation $(p=0.047)($ Table XV).

\section{DISCUSSION:}

People come to health facilities to be cured from disease and injuries. Many of their diseases are caused by microorganisms. Therefore, health facilities are places with a high incidence of disease-causing micro- organisms which are easily spread from patient to patient and by the staff and equipment and other materials used for patient care. The present study aimed at describing the state of hospital-acquired infection in $\mathrm{CMH}$, Dhaka, Bangladesh and factors influencing it. As the study was conducted in CMHs, a sizable portion of the patients was admitted with musculoskeletal diseases due to their exposure to rigorous physical activities. Overall, the study found that HAI constituted a major avoidable health problem in the hospital which causes significant economic sequel, patients sufferings \& administrative inconveniences. The HAI was commonly found in ICU $(41.7 \%)$, followed by BMT ward $(20 \%)$, General Surgery (17.2\%), Urology ward $(13.6 \%)$, Orthopedics ward $(9.6 \%)$.

In the present study, hospital-acquired infection (HAI) at the time of data collection was $12 \%$ and the number of people at risk of HAI were 200 which is close to the findings of Sridhar et al. ${ }^{7}(10 \%)$, Khan et al. ${ }^{8}(11.3 \%)$ in Dhaka Medical College Hospital. However, Hussain ${ }^{9}$ in Dhaka Medical College Hospital demonstrated HAI to be much higher(30\%). The difference may be due to the fact that military hospitals had a sound administration to take care of the risk factors for HAI and appropriate application of aseptic practices. Andersen et al. ${ }^{10}$ in their study showed that in Norway, the overall hospital acquired infection rate to be $6 \%$. Amin and Nahar ${ }^{6}$ in Dhaka $\mathrm{CMH}$ showed the prevalence of HAI $(8.3 \%)$ to be less than that from the present study. Out of $24(12 \%)$ cases of HAI, $50 \%$ were surgical site infection (SSI), $25 \%$ urinary tract infection (UTI), $16.7 \%$ respiratory tract infection (RTI), $4.1 \%$ skin and soft tissue infection (SSTI), 4.1\% blood stream infection (BSI), pneumonia $12 \%$, skin and soft tissue infection (SSTI) $10 \%$, blood stream infection (BSI) $9 \%$. The difference in the findings might be due to the fact that different hospitals, even variation among countries, there are wide variety of practices with regard to clean surgical procedures, use of invasive devices and knowledge \& practices among hospital staffs for aseptic patient handling.

The present study found no association between socio-demographic factors and development of HAI. Patients who underwent surgery had a higher incidence of HAI $(17.3 \%)$ than those who did not undergo surgery $(p=0.023)$. The present study conformed to the findings of Afroz et al. ${ }^{11}$ where association between surgery and development of HAI was found statistically significant $(p<0.05)$. The study also demonstrated that patients who used invasive device tend to be associated with HAI, which is further strengthened by the fact that more the duration of invasive device use, the more is the chance of HAI bearing consistency with the findings of Afrozet al ${ }^{11}$. The study found type of operation to be associated with HAI with emergency operation being more frequently associated with the development HAI. Emergency surgical intervention usually involves inadequate aseptic preparation by the surgical team and the patients needing surgical interventions are usually more vulnerable to develop HAI. The finding is consistent with the finding of Amin \& Nahar ${ }^{6}$ where $34.8 \%$ of emergency operation developed HAI. However, immunosuppressive condition of the patients or patients receiving immunosuppressive therapy were not associated with the HAI which bears consistency with result of Afroz et al. ${ }^{11}$ Respondents who require assistance for most of their daily activities tend to develop HAI more frequently than those who did not require assistance in their daily activities $(p=0.005)$ which is in line with the findings of Amin and Nahar, ${ }^{6}$ where $40 \%$ of the HAI developed in those who needed assistance for most activities. 


\section{CONCLUSION:}

The study concluded that every one in eight patients admitted in $\mathrm{CMH}$ may develop HAI. Neither age nor sex of the patients determines the development of HAI. Patients dependent on others for their daily activities more often develop HAI than those who are independent. Patients inserted with an invasive device and patients of chronic respiratory disease and diabetes mellitus are more prone to develop HAI. Colostomy and gastrostomy tube also act as the main sources of HAI. So does the urinary catheter, orthopedic fixation device and mechanical ventilation with longer the use of invasive devices the higher is the chance of HAI. Immunosuppressive condition of the patients and immunosuppressive therapy development were not found to be associated with HAI. Emergency operation also tends to be associated with HAI. Findings suggest that measures need to be taken to increase awareness of hospital staffs during any aseptic procedure for effective control of HAI. The findings might be useful for the hospital managers and policy-makers to develop policy and strategy to contain the incidence of HAIs. The researcher suggests further in-depth study to find out the causes of increasing HAI in different wards to get a real picture of HAI.

\section{REFERENCES:}

1. WHO. Bulletin of the World Health Organization. 2011; 89(10): 701-776. doi: 10.2471/BLT.11.088179

2. World Health Organization. Prevention of hospital acquired infection. A practical guide. Bull World Health Organ [Internet]. 2002 [cited 2015 Jan 101. 1 p. Available from: http://apps.who.int/medicinedocstdocuments/sl6355e/ sl6355e.pdf

3. Breathnach SA. Nosocomial Bacterial Infection. Medicine International 2001;01(3): 88-90.

4. Shahida SM, Islam A, Dey BR, Islam F, Venkatesh K, Goodman A. Hospital acquired infections in low and middle income countries: root cause analysis and the development of infection control practices in Bangladesh. Open Journal of Obstetrics and Gynecology 2016;6 (01):28.

5. Rahman ASMM. Organisms causing nosocomial infections and their antibiogram isolated from patients of ICU. ICDDR'B, Centre for Health and Population Research, 2002.
6. Amin ZA, Nahar N. Hospital Acquired Infection in a Tertiary Military Hospital in Dhaka, Bangladesh. International Journal of Infectious Diseases and Therapy 2017;2 (2):35-39. doi: 10.11648/j.ijidt.20170202.12

7. Sridhar MR, Boopathi S, Lodha R et al. Standard precautions and post exposure prophylaxis, for a preventing infections. Pediatr J 2004;71:617-626.

8. Khan HM, Miah AK. Outcome of acquired infections in a hospital of Dhaka city. Journal of Preventive and Social Medicine (JOPSOM) 2003;22(2):45.

9. Hussain T, Fazal MA, Ahmed A et al. nosocomial infection-A cross-sectional study in the surgical wards of Dhaka Medical College Hospital. Journal of Preventive and Social Medicine 1991;10(2):10-13.

10. Andersen BM, Rasch M. Hospital-acquired infections in Norwegian long-term-care institutions. A three-year survey of hospital-acquired infections and antibiotic treatment in nursing/residential homes, including 4500 residents in Oslo. J Hosp Infect 2000;46(4):288-96.

11. Afroz $H$, Fakruddin M, Masud MR, Islam K. Incidence of and risk factors for hospital acquired infection in a tertiary care hospital of Dhaka, Bangladesh. Bangladesh Journal of Medical Science 2017;16(3):358-369. 